НАУКИ О ЗЕМЛЕ

"НАУКА. ИННОВАЦИИ. ТЕХНОЛОГИИ", №4, 2019

25.00 .24

УДК 528.946

ЭКОНОМИЧЕСКАЯ, СОЦИАЛЬНАЯ, ПОЛИТИЧЕСКАЯ

И РЕКРЕАЦИОННАЯ ГЕОГРАФИЯ

Махмудов Р.К.,

Черкасов A.A.,

Верозуб Н.В.

ФГАОУ ВО «Северо-Кавказский феедеральный университет»,

г. Ставрополь, Россия

\title{
ГЕОИНФОРМАЦИОННОЕ ПРОЕКТИРОВАНИЕ И ДИЗАЙН КРУПНОМАСШТАБНЫХ ТУРИСТИЧЕСКИХ КАРТ
}

Введение: $\quad$ туристическая карта является необходимым ресурсом для работы с пространственным ориентированием. Ее основная задача - визуализирование туристско-рекреационного потенциала территории, необходимое как для туриста, так и для специалистов, исследователей индустрии туризма. В России особенно актуально создание туристических карт регионов, отдельных туристических кластеров и курортов для развития внутреннего туризма-быстро и активно развивающегося направления в экономике. В работе представлен авторский опыт особенностей создания крупномасштабных туристических карт и планов курортных городов с помощью геоинформационных технологий и графических редакторов. Апробация выявленных особенностей картографирования проводилась на примере города-курорта Кисловодска

Материалы и методы исследований:

Информационной базой для составления туристической карты городакурорта Кисловодска послужили: туристический паспорт и генеральный план города-курорта Кисловодска, реестры объектов культурного наследия федерального и регионального значения, открытые данные Федеральной службы государственной регистрации, кадастра и картографии, данные Министерства природных ресурсов и экологии Российской Федерации.

В качестве базовой ГИС-программы была использована ArcGIS Pro. В качестве дополнительного инструмента визуализации картографических данных использован графический редактор Illustrator.

Результаты исследования

и их обсуждения: туристические карты отличаются прикладным значением отображения территории и ориентированы на массового потребителя, не знакомого с тонкостями научного картографического анализа. При этом стоит брать во внимание, что туристические карты воспринимаются индивидуально. в связи с этим выявлены несколько особенностей их проектирования: простота, красочность изображаемых объектов, необходимость построения 3-D моделей на территории, где рельеф-основной природно-рекреационный ресурс, использование интуитивных цветов при отображении поверхностей.

Выводы: $\quad$ выявленные особенности и методика геоинформационного проектирования туристических карт были апробированы при разработке макета крупномасштабной туристической карты города-курорта Кисловодска. В ходе работы были обозначены особенности планировочной организации города для картографирования туристско-рекреационной ресурсов и условий, а так же проведена геоинформационная оценка потенциальной аудитории пользования туристическими картами.

Ключевые слова: туристические карты, крупномасштабные карты, способы изображения, туристический маршрут. 
Mahmudov R.K., Cherkasov A.A., Verosub N.V.

Introduction
North Caucasus Federal University,

Stavropol, Russia

\section{Geo-Information Design and Large-Scale Tourist Maps}

A tourist map is a necessary resource for working with spatial orientation. Its main task is to visualize the tourist and recreational potential of the territory, which is necessary both for tourists and for specialists and researchers in the tourism industry. In Russia, the creation of tourist maps of regions, individual tourist clusters and resorts for the development of domestic tourism, a rapidly and actively developing direction in the economy, is especially important. The paper presents the author's experience of creating large-scale tourist maps and plans for resort cities using geo-information technologies and graphic editors. Testing of the identified features of mapping was carried out on the example of the resort town of Kislovodsk.

Materials and research methods: ArcGIS Pro was used as the base GIS program. The graphical editor Illustrator is used as an additional tool for visualizing cartographic data. The information base for compiling the tourist map of the resort town of Kislovodsk was: registers of cultural heritage sites of federal and regional significance, open data of the Federal State Registration Service, cadastre and cartography, data of the Ministry of Natural Resources and Environment of the Russian Federation.

The results of the study and their discussion: tourist maps are distinguished by the applied value of displaying the territory and are aimed at the mass consumer who are not familiar with the intricacies of scientific cartographic analysis. It is worth taking into account that tourist cards are perceived individually. In this regard, several features of their design were identified: simplicity, brilliance of the objects depicted, the need to build 3-D models in the territory where the relief is the main natural recreational resource, the use of intuitive colors when displaying surfaces

Conclusions: the identified features and methods of geographic information design of tourist maps were tested during the development of the layout of a large-scale tourist map of the resort city of Kislovodsk. In the course of the work, the features of the planning organization of the city for mapping tourist and recreational resources and conditions were identified, as well as a geo-informational assessment of the potential audience for using tourist maps was carried out.

Keywords:

\section{Введение}

Регион Кавказских Минеральных вод (КМВ) располагает значимыми туристско-рекреационными ресурсами (природно-климатическими, историко-культурными, материально-техническими и др.). Рекреационная деятельность исторически является основной отраслью хозяйственной специализации региона и имеет все предпосылки для дальнейшего развития. Анализ документов стратегического и территориального планирования Северо-Кавказского федерального округа, Ставропольского края, городов КМВ подтверждает значимость и демонстрирует амбициозные намерения по развитию санаторно-курортного, рекреационно-туристического комплекса региона. 
Картографо-геоинформационные технологии является признанными и эффективными инструментами по продвижению туристических территорий. Моделирование туристической карты с помощью ГИС-технологий позволяет осуществлять привязку к местности, сохранять правильную ориентацию в пространстве, формировать базу данных об объектах туризма, а также учитывать пространственную организацию территории, в том числе границы и расстояния между объектами в нужном масштабе.

Крупномасштабные туристические карты (планы) городов - это изображение городской среды для удовлетворения интересов и потребностей туриста. Такие типы карт отличаются тем, что помимо объектов туризма отражают нетуристические постройки, территории, являющиеся неотьемлемой частью города и складывающие общий облик улищы, а значит необходимые для ориентирования туриста в городе.

Городское туристское картографирование - одно из актуальных направлений урбанистической визуальной и медийной культуры. Принципы и особенности городской картографии заключаются в избирательности, сюжетности, контекстности, крупномасштабности и уникальности [11].

Туристические карты относятся к самостоятельной, отдельной категории картографических изображений. Среди множества типов карт (общегеографических, геологических, почвоведческих, космических и др.), их можно отнести по своему значению к экономико-географическому картографированию элементов социального комплекса. Однако они отличаются прикладным назначением отображения территорий [9].

Геоинформационное проектирование и дизайн крупномасштабной туристической карты апробирован авторами на примере города-курорта Кисловодска, как наиболее интересного с позиции туриста (подтверждает контент анализ запросов туристических сайтов), так и сточки зрения приоритетного развития курортов Кавказских минеральных вод.

\section{Материалы и методы исследований}

Авторским коллективом была создана геоинформационная система по мониторингу туристической деятельности городского округа города-курорта Кисловодска. Данная ГИС решает задачи по изучению туристических потоков, формирования зон и точек интересов туриста, содержит развернутую информацию о туристических объектах, имеют инструментарий, позволяющий применять различные методы визуализации, осуществлять моделирования и картографирование городских пространств.

В качестве базовой ГИС-платформы используется ArcGIS Pro, обладающий широкими возможностями для картографирования в различных масш- 


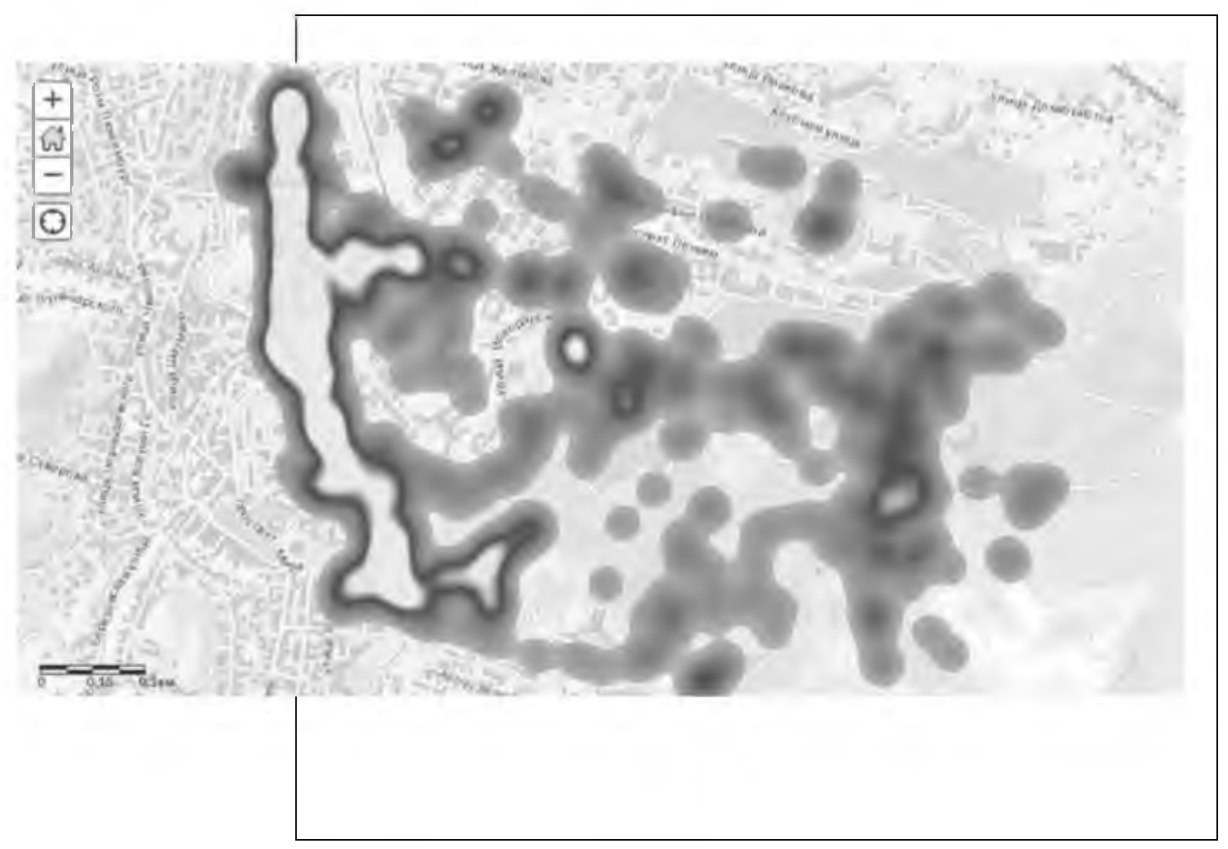

Рис. 1.

\section{Места наибольшей концентрации туристов в пределах исторического центра города-курорта Кисловодска.}

Fig. 1. Places of the greatest concentration of tourists within the historical center of the resort city of Kislovodsk

табах, а также проведения анализа данных способом тепловых карт. С целью построения цифровой модели рельефа (ЦМР) использовалась открытая геоинформационная система QGIS, модуль Qgis2theejs Explorter. В качестве базового инструмента конечной визуализации картографических данных применяется векторный графический редактор Adobe Illustrator.

При подготовке туристической карты города-курорта Кисловодска применялся набор картографических способов изображения. В качестве основного выступил способ знаков, применяемый для отображения объектов санаторно-курортного лечения, памятников истории и культуры, иных зданий и сооружений локализованных в городе.

База данных системы по мониторингу туристической деятельности городского округа города-курорта Кисловодска была структурирована и представляет собой систематизированный набор объектов: 
Памятники природы, истории и архитектуры;

Общественные пространства: парки, скверы, пешеходные зоны;

- $\quad$ Средства коллективного размещения: санатории, гостиницы, хостелы.

- $\quad$ Места общественного питания;

- $\quad$ Объекты транспортной инфраструктуры: автомобильные и железные дороги, здания вокзалов, остановки общественного транспорта, парковки;

Здания жилой застройки, прилегающей к историческому центру.

Основным информационным источником в которой рассматриваются изобразительные средства, свойства, восприятие, правила применения технической и художественной графики, цвета, цветовой и светотеневой пластики при проектировании картографических произведений. послужила работа Востоковой А.В., Кошель С.М., Ушаковой Л.А. «Оформление карт. Компьютерный дизайн».

Важными источниками информации стали документы территориального и стратегического планирования, в частности «Схема территориального планирования Ставропольского края», «Стратегия развития городского округа города-курорта Кисловодска» «Генеральный план городского округа», которые отражают существующее состояние и направления развития туристической сферы, как основной отрасли экономики городского округа. В схеме территориального планирования возможно проследить имеющиеся туристические ресурсы и объекты культурного наследия, отраженные в карте современного использования территории, а так же планируемые объекты капитального строительства регионального и федерального значения в сфере туризма и рекреации.

Согласно генеральному плану городского округа, планируется строительство новых санаторно-курортных комплексов, реконструкция объектов культурного наследия, входящих в основной туристический маршрут, проведение озеленений ряда улиц и строительство карманньх скверов, строительство велодорожек. Анализ карт планируемого развития генерального плана, позволяет выделить основные районы развития туристской инфраструктуры, а так же планировать и отображать туристические маршруты, с учетом будущего городского благоустройства.

Наиболее ярким примером дизайна и проектирования является туристическая карта Ставропольского края, выполненная коллективом студентов и 
преподавателей СКФУ, которая визуализирует туристический потенциал края и показывает основные туристические доминанты населенных пунктов.

\section{Результаты исследований и их обсуждение}

На первом этапе работ по подготовке крупномасштабной туристической карты города-курорта Кисловодска был проведен анализ территориальной структуры города. Так город состоит из 15-ти микрорайонов, 5 из них имеют туристско-рекреационное назначение. Около $50 \%$ городской застройки относится к частному сектору, $20 \%$ занято средне этажными и многоэтажными жилыми домами. Такие районы не несут туристической ценности, а значит, на начальном этапе проектирования туристической карты необходимо ограничить территорию крупномасштабного изображения.

Для определения наиболее популярных мест среди туристов применялся метод анализа геотегов. В качестве основного инструмента анализа использовался инструмент «Горячие точки» программы ArcGIS Pro (рис. 1). В результате были определены улицы с наибольшим пешеходным туристическим потоком, и места притяжения в пределах туристических районов города (исторического центра и кисловодского национального парка).

На втором этапе была создана 2-х мерная картографическая основа, с нанесением объектов, складывающих основу карты: гидрографической сети, дорог, улиц, растительности, жилой застройки, историко-культурных и природных достопримечательностей.

Рельеф города-курорта разнообразен и вместе с лечебными минеральными источниками является одним из главных рекреационных ресурсов территории, и используется для организации лечебных терренкуров, пешеходных и вело-маршрутов.

Для наибольшей наглядности и необходимости визуализации туристского контента территории города был осуществлен переход от двумерной модели к 3-мерной цифровой модели рельефа (Рисунок 2). Использование ЦМР для создания туристических карт позволяет приблизить к реальности картографируемую территорию для наилучшего ее восприятия туристом на местности.

В этой связи для наибольшей наглядности и визуализации туристической территории города был осуществлен переход от двумерной модели к $3-\mathrm{x}$ мерной цифровой модели рельефа (рис. 2). Использование ЦМР для создания туристических карт позволяет приблизить к реальности картографируемую территорию для наилучшего ее восприятия туристом на местности.

При изображении трехмерного объекта на плоскости его форма была смоделирована теневыми переходами, поэтому для того, чтобы обеспечить 


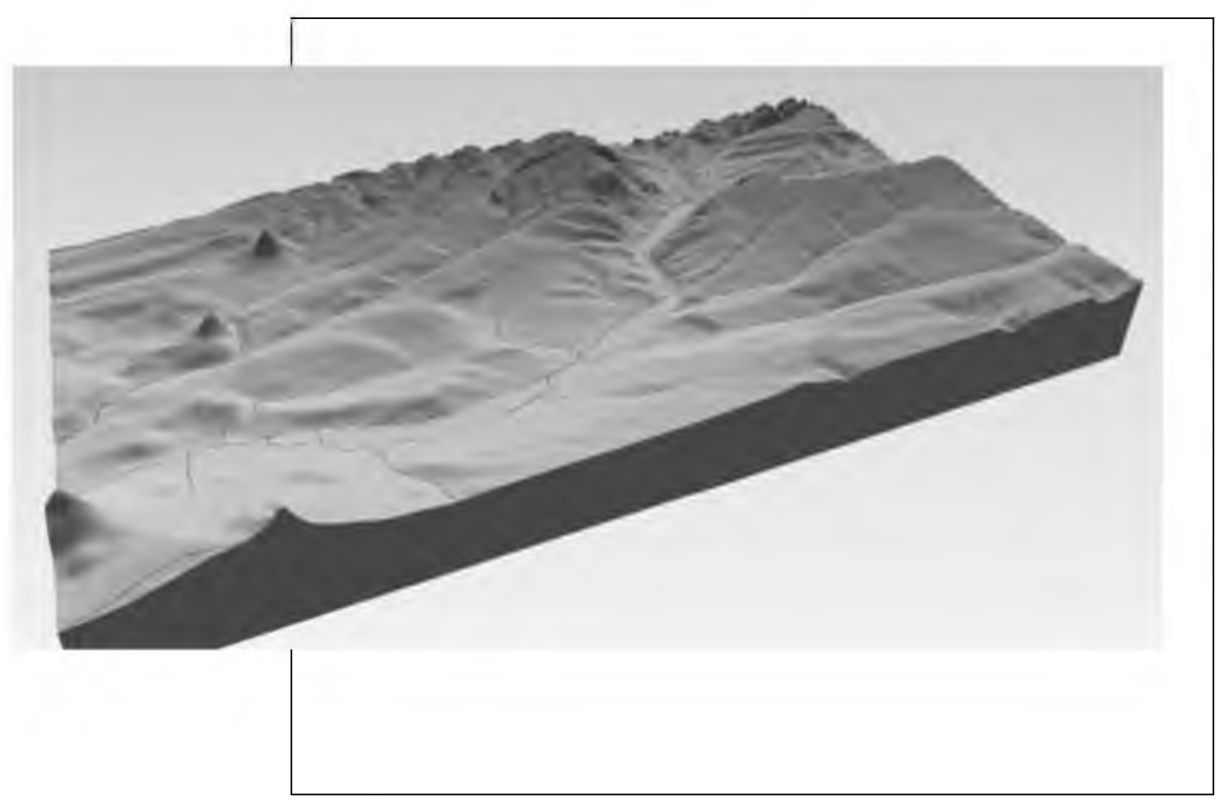

Pис. 2.

Цифровая модель рельефа Кисловодской котловины.

Fig. 2. Digital relief model of the Kislovodsk basin.

правильное восприятие объекта, необходимо соблюдать законы построения светотени, а при работе в графическом редакторе - применять рациональные алгоритмы создания нужного эффекта [11]. Построение теней на графических изображениях обеспечивает большую наглядность, усиливает объемно-пространственное восприятие, подчеркивает рельефность и эффект перспективы. ГИС-пакеты обладают широкими возможностями по работе с пространственными данными их анализе и хранении, точной привязке к местности, создании ЦМР, но не всегда удовлетворяют необходимость художественного оформления построенной картографической модели.

Третий этап - графическая, детальная проработка всех отображаемых объектов местности. Оригинальное художественное оформление - один из главных критериев при создании туристических карт для людей, далеких от картографии и понимания специальных, научных или топографических обозначений объектов местности.

Различают 3 этапа осмотра и восприятия туристической карты человеком, далеким от области картографирования: 
первый этап включает в себя первичный осмотр изображения, ориентацию в пространстве, т.е. нахождение частей света и своего местоположения, оценку расстояния до выбранного объекта посещения, способов проезда;

на втором этапе происходит увеличение получаемой информации. Турист визуально привыкает к способам изображения, свободно владеет условными знаками, находит опорные точки своего маршрута до выбранного объекта, уточняет маршрут;

третий этап характеризуется складыванием полного образа территории в сознании человека и закрепление его в памяти [15].

Одной из самых главных характеристик при создании туристической карты является цвет. Он расширяет возможности восприятия значков и других способов изображения действительности. Цвет позволяет использовать эффекты теневой пластики.

Использование цвета на карте имеет условный и символический смысл. Как условное обозначение цвет воспринимается в зависимости от конкретных отображаемых явлений. Например, на общегеографической карте голубой цвет соотносится с территориями, занятыми гидрографическими объектами, коричневый ассоциируется с рельефом местности [8].

Выбор цветового оформления изображений осуществляется по принципу сходства с реальными природными объектами для того, чтобы на интуитивном уровне быть понятным человеку - не профессионалу.

Цвет наглядно передает качественные и количественные характеристики природных и историко-культурных объектов на туристических картах. Качественная сторона проявляется в таких способах изображения как цветовой фон, ареалы, линейные знаки и др.; количественная - особенно ярко проявляется в способах цветового оформления количественного фона, например, рельефа местности.

Туристические карты ориентированы на массового потребителя, не знакомого с тонкостями научного картографического анализа. В связи с этим на таких картах, как правило, отсутствуют изображения статистических показателей, развития предприятий социальной сферы и инфраструктуры. Они не предназначены для проведения научного анализа состояния и развития туризма. Их главная цель - помочь потенциальным туристам сориентироваться в пространстве, проложить экскурсионный маршрут, осознать масштабы и расстояния своего путешествия, распределить своё время на осмотр туристических объектов. 
Туристические объекты и объекты туристической инфраструктуры на картах изображают различными способами. В картографии существует четкая классификация способов изображения действительности. В разработанной туристической карте использовались следующие способы изображения:

Способ значков - символическое обозначение объектов местности, не соответствующее масштабу карты [4]. На разрабатываемой карте города-курорта Кисловодска объекты отображены двумя типами значков: уникальные, наглядные значки (иллюстрации), напоминающие изображаемый объект и абстрактные геометрические-не сходные по конфигурации с изображаемым объектом, требующие обязательной расшифровки в легенде карты.

Уникальные изображения отличаются красочной, детальной прорисовкой не имеют себе подобного. Они создавались максимально понятными для туриста на интуитивном уровне. Такие знаки не выносятся в текстовое описание и легенду, и отображают особенности каждого объекта. Подобными знаками обозначены архитектурные постройки городов, церкви, монастыри или неповторимые природные объекты (например, Гора-Кольцо, Скала-Дракон и др.). Второй тип объектов отображен внемасштабными знаками, обозначающими объекты одного типа выполняющие одинаковые функции (например, любой источник пресной воды, медицинские учреждения, парковки и т.д) (рис. 3). Способ линейных знаков. Разный рисунок и цвет линейных знаков передают качественные и количественные характеристики объектов. Данным способом на карте отображены линии терренкуров и туристической тропы Косыгина. Линейные знаки вне масштабны, но повторяют оси существующих на местности объектов [4]. На проектируемой карте из-за крупного масштаба линейные объекты, например дороги и реки заменяются площадными .Это улучшает восприятие перспективы улиц, позволяет отобразить здания в необходимом для узнавания ракурсе и создает наиболее реалистичное отображение местности (рис. 3)

Способ качественного фона на картографических изображениях показывает явления сплошного распространения. На разрабатываемой туристической карте данный способ применяется для отображения растительного покрова и теневой пластики рельефа (рис. 3).

\section{Выводы}

В ходе геоинформационного проектирования и подготовки дизайн макета крупномасштабной туристической карты города-курорта Кисловодска были выделены следующие этапы:

Анализ территориальной структуры города. Выделение зон наибольшей конщентрации туристических объектов; 


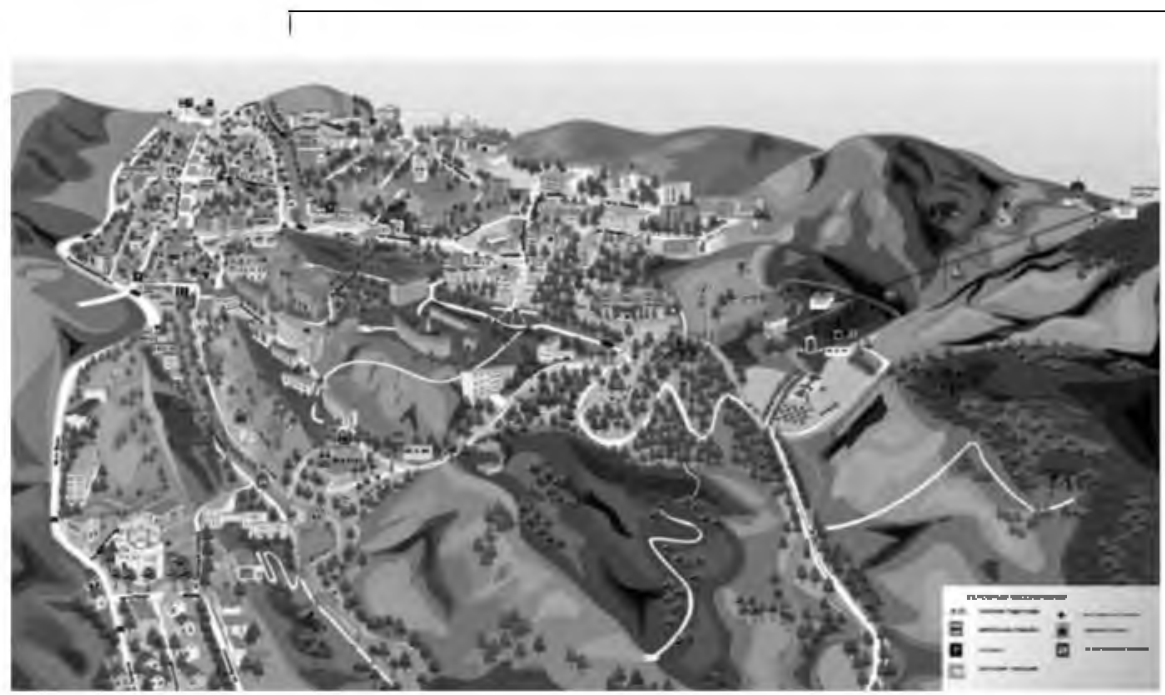

1

Рис. 3.

\section{Фрагмент туристической карты города-курорта Кисловодска.}

Fig. 3. A fragment of the tourist map of the resort city of Kislovodsk.

- $\quad$ Построение 3-х мерной цифровой основы города;

- Графическая проработка всех отображаемых объектов местности.

Туристская карта является необходимым ресурсом для пространственного ориентирования незнакомого с местностью туриста.

Анализ геотегов социальных сетей на выбранную для картографирования часть города показывает, что основной возраст туристов - от 18 до 30 лет. Отсюда можно сделать вывод, что основная аудитория разработанной карты - молодые люди, студенты, т.е. туристы предпочитающие «дешевый» однодневный экскурсионный или спортивный туризм, а так же молодые семьи с детьми, для которых территория исторического центра и нижней части национального парка, является оптимальной по сложности для прохождения маршрута.

Кроме того, к историческому центру прилегают районы лечебных санаториев, основной возрастной контингент которых лица от 40 до 70 лет. Т.е люди, предпочитающие бумажные информационные источники электронным. 
В целом созданная карта позволяет решать следующие задачи:

- Донести туристу информацию о туристско-рекреационных объектах города-курорта Кисловодска;

- $\quad$ Организация и планирование маршрута следования;

- $\quad$ Предупреждение и информирование об особенностях местности во время нахождения в полевых условиях.

Созданный вариант карты-схемы города-курорта Кисловодска включает в себя актуальную информацию о достопримечательностях города, которая была визуализирована с учетом всех необходимых правил и параметров, использующихся при составлении подобных тематических карт. Итоговый вариант бал макетирован и выполнен в виде складной карты.

\section{Библиографический список}

1. Востокова А.В., Кошель С.М., Ушакова Л.А. Оформление карт. Компьютерный дизайн.

2. Генеральный план города-курорта Кисловодска.

3. Гусейн-Заде С.М., Тикунов В.С. Визуализация в неевклидовых метриках. Китайский университет Гонконга, Гонконг, 2015.

4. Зейлер М. Моделирование нашего мира. Руководство ESRI по проектированию базы геоданных. Нью-Йорк, ESRI Press, 1999. $254 \mathrm{c}$.

5. Схема территориального планирования Ставропольского края.

6. Гладкий А.В., Скляров А.А.. Современные картографические модели и особенности их использования в туризме // Псковский регионологический журнал. № 1 (29). 2017.

7. Иттен И. Искусство цвета // Издатель Д. Аронов. М., 2004.

8. Краак М.-Я., Ормелинг Ф. Картография: визуализация геопространственных данных. М.: Научный мир, 2005. 325 c.

9. Полевой К. Картографрия. Esri Press, Редлендс, Калифорния, 2018

10. Лурье И. К., Самсонов Т. Е. Структура и содержание базы пространственных данных для мультимасштабного картографирования // Геодезия и картография. 2010. № 11. 17-23 с.

11. Махмудов Р.К., Стоек Ю.О., Черкасов А.А. Проектирование и составление туристской карты Ставропольского края // Геоинформационное обеспечение устойчивого развития территорий в условиях глобальных изменений климата: материалы международной конференции «ИнтерКарто/ИнтерГИС-22»; Т. 2. Протвино, 2016. 166-174 с. 
12. Мошняга Е.В. Концептуальное пространство межкультурной коммуникации в туризме в условиях глобализации: монография. М.: Советский спорт, 2010. 52 с.

13. Панин А.Н., Тикунов В.С., Фурщик М.А. Геоинформационное обеспечение туризма в России. Подходы, методы, технологии. Изд-во Диалог культур, 2014.

14. Петрановский В. Л. Рутинский М. И.. Туристическое краеведение // Изд-во «Знания», 2006.

15. Розанова Ю. Н. Путеводитель как жанр туристического дискурса: даихронический аспект // Историческая и социально-образовательная мысль. 2014. № 5 (27). 281 с.

16. Тикунов В.С., Белозеров В.С., Антипов С.О., Супрунчук И.П Социальные медиа как инструмент анализа посещаемости туристических объектов (на примере Ставропольского края) // Вестник Московского университета. Серия 5: География, издательство Изд-во Моск. ун-та (М.), №3. 89-95 с.

17. Тикунов В., Белозеров В., Панин А., Антипов С. Геоинформационный мониторинг ключевых запросов поисковых систем и геотеггинг фотографий в северокавказском сегменте туристического маршрута «Великий шелковый путь» // Летопись ГИС. 24. (2018).

\section{References}

1. Vostokova A.V., Koshel' S.M., Ushakova L.A. Oformleniye kart Komp'yutemyy dizayn.( Card design. Computer design).

2. General'nyy plan goroda-kurorta Kislovodska (The general plan of the resort city of Kislovodsk)

3. Huseyn-Zade S.M., Tikunov V.S. Vizualizatsiya $\vee$ neyevklidovykh metrikakh (Visualization in non-Euclidean metrics ) // Chinese University of Hong Kong, Hong Kong, 2015.

4. Zeiler M. Zeyler M. Modelirovaniye nashego mira (Modeling our world) // ESRI Geodatabase Design Guide. New York, ESRI Press

5. Skhema territorial'nogo planirovaniya Stavropol'skogo kraya (Spatial planning scheme for the Stavropol Territory)

6. Gladky A.V., Sklyarov A.A. Sovremennyye kartograficheskiye modeli i osobennosti ikh ispol'zovaniya $v$ turizme (Modern cartographic models and features of their use in tourism) // Pskov Regional Journal No. 1 (29) / 2017.

7. Itten I. Iskusstvo tsveta (The Art of Color) // Publisher D. Aronov; M., 2004.

8. Kraak M.-J. Ormeling F. Ormeling F. Kartografiya: vizualizatsiya geoprostranstvennykh dannykh (Cartography: visualization of geospatial data) // M .: Scientific World

9. Field K. Kartografiya (Cartography). Esri Press, Redlands, California, 2018 
10. Lur'e I.K., Samsonov T.E. Struktura i soderzhanie bazy prostranstvennyh dannyh dlya mul'timasshtabnogo kartografirovaniya (Structure and content of the spatial database for multiscale mapping) // Geodeziya i kartografiya. 2010. № 11. S. 17-23 p. (in Russian).

11. Makhmudov R.K., Stoyok Yu.O., Cherkasov A.A. Proyektirovaniye i sostavleniye turistskoy karty Stavropol'skogo kraya (Design and compilation of a tourist map of the Stavropol Territory ) // Geoinformation support for sustainable development of territories in the context of global climate change: materials of the international conference "InterCarto / InterGIS - 22; T. 2. Protvino, 2016, p. 166. $174 p$.

12. Moshnyaga E.V. Kontseptual'noye prostranstvo mezhkul'turnoy kommunikatsii $\vee$ turizme $v$ usloviyakh globalizatsii: monografiya (Conceptual space of intercultural communication in tourism in the context of globalization: a monograph) // M.: Soviet Sport, 2010.

13. Panin A.N., Tikunov V.S., The coachman M.A. Geoinformatsionnoye obespecheniye turizma $\vee$ Rossii (Geoinformation support of tourism in Russia. Approaches, methods, technologies) // Dialogue of Cultures, 2014

14. Petranovsky V.L. and Rutinsky M.I. Turisticheskoye krayevedeniye (Tourist study of local lore) // Publishing house)"Knowledge" 2006.

15. Rozanova Yu. N. Putevoditel' kak zhanr turisticheskogo diskursa: daikhronicheskiy aspekt (A guidebook as a genre of tourist discourse: the daichronical aspect ) // Historical and socio-educational thought. 2014. No 5 (27). $281 \mathrm{p}$.

16. Tikunov V.S., Belozerov V.S., Antipov S.O., Suprunchuk I.P. Sotsial'nyye media kak instrument analiza poseshchayemosti turisticheskikh ob"yektov (na primere Stavropol'skogo kraya) (Social media as a tool for analyzing the attendance of tourist sites [for example, the Stavropol Territory]) // Moscow University Herald. Series 5: Geography, publishing house Publishing house Mosk. University (M.), No. 3, 89-95 s.

17. Tikunov B., Belozerov B., Panin A., Antipov S. Geoinformatsionnyy monitoring klyuchevykh zaprosov poiskovykh sistem i geotegging fotografiy $v$ severokavkazskom segmente turisticheskogo marshruta "Velikiy shelkovyy put'» (Geoinformation monitoring of key queries of search engines and geotagging of photographs in the North Caucasian segment of the Great Silk Road tourist route) /I Chronicle of GIS. 24. (2018).

Поступило в редакцию 28.10.2019, принята к публикации 02.09.2019. 


\author{
06 авторах \\ Махмудов Раким Камилович, кандидат географических наук, доцент ка- \\ федры социально-экономической географии и туризма Севе- \\ ро-кавказского федерального университета. \\ E-mail: rakimkam@mail.ru. \\ Черкасов Александр Александрович, кандидат географических наук, \\ доцент кафедры социально-экономической географии, геоин- \\ форматики и туризма Северо-Кавказского федерального уни- \\ верситета. \\ Scopus ID: 57192379694 . \\ Researcher ID: 57192379694. \\ E-mail: cherkasov_stav@mail.ru \\ Верозуб Наталья Владимировна, студентка 2-го курса магистратуры \\ специальности 05.04 .03 «Картография и геоинформатика». \\ E-mail: verozub_95@mail.ru.
}

\section{About the authors}

Makhmudov Rakim Kamilovich, Candidate of geographical sciences, associate professor of the department of socio-economic geography and tourism of the North Caucasus Federal University.

E-mail: rakimkam@mail.ru.

Cherkasov Alexander Alexandrovich, Candidate of geographical sciences, associate professor of the department of socio-economic geography, geoinformatics and tourism of the North-Caucasus federal university.

Scopus ID: 57192859694.

Researcher ID: 57192379694.

Phone: +7(906) 460-99-98.

E-mail: cherkasov_stav@mail.ru

Verozub Natalya Vladimirovna, 2nd year student of the magistracy specialty 05.04.03 "Cartography and geoinformatics".

E-mail: verozub_95@mail.ru. 